\title{
A fresh look at depolarisation criteria for cathodic protection of steel reinforcement in concrete
}

\author{
Nikita Rathod $^{1}$, Peter Slater ${ }^{1}$, George Sergi ${ }^{2}$, Gamini Seveviratne ${ }^{2}$ and David Simpson ${ }^{2}$ \\ ${ }^{1}$ School of Chemistry, Birmingham University, Edgbaston, Birmingham B15 2TT, UK \\ ${ }^{2}$ Vector Corrosion Technologies Ltd, 27a Upper High Street, Cradley Heath, West Midlands B64 5HX, UK
}

\begin{abstract}
Criteria for the successful application of cathodic protection (CP) for steel reinforced concrete have been fixed for decades and form part of ISO EN12696. The most used criterion is the achievement of $100 \mathrm{mV}$ depolarization over a period not exceeding 24 hours after discontinuation of the applied current. Although more empirical than theoretically based, the criterion has served the CP industry well. It does, however, exclude any systems that may not always achieve that level of depolarization but have been shown to offer adequate protection, and so there is a need to explore ways of assessing depolarisation data more effectively. On a fundamental level, non-linear polarisation, as described by the Butler Volmer equation, relates corrosion rate to polarisation for a given applied current density and shows that at low current densities, estimated corrosion rates can be shown to be still insignificant at less than $100 \mathrm{mV}$ polarisations. This paper explores the use of nonlinear polarisation as an additional supportive criterion based on the measured 24-hour depolarisation level for a known applied current density and tests its applicability in the laboratory and in the field. It speculates that a reducing apparent corrosion current density trend in combination with a depolarised potential moving in a more noble direction is likely to be a suitable alternative criterion, where $100 \mathrm{mV}$ depolarisation is not achieved.
\end{abstract}

\section{Introduction}

Both ISO EN $12696: 2016$ [1] and NACE SP0290 : 2007 [2] have a set of criteria that need to be satisfied to specify that a cathodic protection system is deemed to be adequately protecting the steel reinforcement. Meeting the criteria is believed to be an indication that the system is delivering satisfactory cathodic current to either passivate the reinforcing steel or reduce its corrosion current to low and non-destructive levels.

Polarising any metal to a near immunity state is recognised as a possible way of achieving protection hence ISO EN 12696 requires, as one of its criteria, achieving an instantaneous-off potential of $-720 \mathrm{mV}$ vs Silver-Silver chloride reference electrode, $0.5 \mathrm{M} \mathrm{KCl}$. In saturated concrete this level of polarisation is achieved easily so the standard also tries to ensure that the steel potential does not fall much below this value, especially for prestressing steel so it sets a limit of $-900 \mathrm{mV}$ vs Silver-Silver chloride reference electrode, $0.5 \mathrm{M} \mathrm{KCl}$, in order to avoid hydrogen gas evolution on the steel surface.

Unlike steel in aggressive aqueous or soil environments, in concrete, steel forms a protective oxide film owing to the alkalinity of the cement matrix so corrosion, if caused by chlorides, only occurs once the pitting potential is exceeded. To repassivate the steel, it is not essential to polarise the steel to immunity but to the repassivation potential which requires considerably lower cathodic current [3]. Both Standards, allow for this lower polarisation but only by an empirically determined criterion of $100 \mathrm{mV}$ depolarisation (excluding the IR drop) over a period of 24 hours. Such a level of polarisation can be assumed to reduce the corrosion rate roughly by an order of magnitude. In concrete, 24 hours is rarely enough time to achieve full depolarisation of the steel owing primarily to a slow migration of oxygen to the steel surface, especially in partly saturated concrete cover. ISO EN 12696 deals with this possibility by allowing a depolarisation period longer than 24 hours and up to several days provided the level of depolarisation exceeds $150 \mathrm{mV}$.

ISO EN 12696 hints that the criteria are empirical by stating in Note 4 that "Criteria, a), b) and c) (relating to the polarisation/ depolarisation criteria) are not necessarily supported by theoretical considerations, but are a non-exhaustive, practical series of criteria to indicate adequate polarization which will lead to the maintenance or re-establishment of protective conditions for the steel within the concrete".

A NACE International Publication [4] attempted to validate the $100 \mathrm{mV}$ criterion both theoretically and empirically with a level of success in the case of buried pipelines. The document concluded that a $100 \mathrm{mV}$ depolarisation of steel in concrete over a maximum of 24 hours is likely to equate to a total depolarisation of $150 \mathrm{mV}$ over a longer period, which justifies the ISO EN 12696 specification of this higher depolarisation level for periods longer than 24 hours. According to Bennet and Mitchell [5], this level of depolarisation may be required in most aggressive conditions based on a suggestion that 
the cathodic Tafel slope of steel in concrete may be as high as $150 \mathrm{mV} /$ decade which represents an order of magnitude reduction in the corrosion rate.

Apart from these depolarisation criteria, very little else is suggested in the standards that can aid in the validation of a cathodic protection system. There are suggestions of the range of current density $\left(2-20 \mathrm{~mA} / \mathrm{m}^{2}\right)$ that would normally be applied to steel in a CP system, but the actual applied current is normally adjusted post commissioning in an impressed current CP system (ICCP) to achieve the required depolarisation levels.

NACE SP0290 assumes that CP is no longer required if the steel potential is less negative than $-200 \mathrm{mV}$ vs copper/copper sulphate electrode (CSE) and ISO EN 12696 states in Note 5 "As an investigative criterion it may be considered appropriate to seek a steel/concrete potential in a fully depolarized structure after the cathodic protection system has been switched off for a long period (typically 7 days or longer) less negative than $-150 \mathrm{mV}$ with respect to $\mathrm{Ag} / \mathrm{AgCl} / 0.5 \mathrm{M} \mathrm{KCl}$ ”.

It is reasonable to suggest that at the instance when the steel potential is shown to be passive there would be no obvious need to apply further polarisation other than to prevent re-initiation of corrosion with time so a cathodic prevention level current density, suggested as $0.2-2 \mathrm{~mA} / \mathrm{m}^{2}$ in ISO EN 12696, would suffice. Often, the levels of polarisation will be less than $100 \mathrm{mV}$ in such instances.

There are also numerous cases when the depolarisation criteria cannot be met either because current distribution is variable owing to localised irregularities in resistance, or, more commonly, because the current output of the protective system is limited such as when galvanic cathodic protection systems are used or aging ICCP anode systems can no longer adequately deliver the required current. It may be justifiable to maintain a lower current density if it can be shown that adequate protection is maintained. In such cases, it is essential that alternative ways of determining whether the steel reinforcement is adequately protected at any given time are identified.

This paper reports on ways that analysis of site data, such as the relationship between the applied current density to the level of depolarisation and/or the trend of the depolarised potential with time can help assess the adequacy of the level of protection. Site data are supported by laboratory studies where corrosion rates estimated by non-linear polarisation, as defined by the Butler Volmer equation, were compared to equivalent corrosion rates determined by linear polarisation.

\section{Site Data}

Three bridge abutment sites in the UK which had galvanic anodes embedded in concrete for controlling the corrosion of the steel reinforcement were monitored over a period of between 15 and 19 years. The results were analysed carefully, observing trends and apparent corrosion rates to analyse their performance.

\subsection{Site-1, M53 Motorway Bridge, South Clatteridge}

Chloride-laden water sprayed from adjacent traffic of the motorway was causing corrosion concerns of the base of two adjacent abutments of a bridge (Fig. 1). Corrosion potentials were indicative of a low and variable degree of corrosion but there were no signs of corrosion-induced cracking. Two lines of galvanic anodes were embedded in holes broken away at a spacing of approximately $300 \mathrm{~mm}$, 11 No. Size-1 cylindrical anodes in Abutment-1 (Fig.1) and 8 No. Size-2 cylindrical anodes (double current output compared to Size-1 anodes) in Abutment-2.

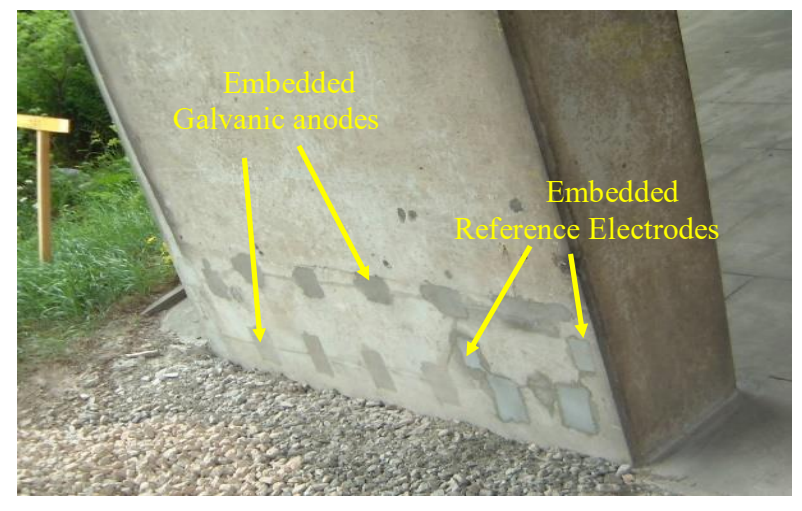

Figure 1 Abutment-1 of a bridge on M53 showing two lines of 11 galvanic anodes and two reference electrodes.

The anodes were connected along a chain of double insulated cable and the two end points of the chain taken to a junction box/monitoring unit at the back of the abutment. Two embeddable silver/silver chloride $0.5 \mathrm{M}$ $\mathrm{KCl}$ reference electrodes were also inserted in holes at anode midpoint locations. The cables of these and from two connections to the steel reinforcement were also taken to the monitoring box which enabled connection and disconnection between the anodes and the steel reinforcement. This allowed monitoring of the current flowing between the anodes and the steel, the on and instant-off potentials of the steel by the embedded reference electrodes and the depolarisation potentials over 24 hours after switching off the current.

Results were collected over a period of 15 years. The anodes are still in operation.

\subsection{Site-2, Ivy Street Bridge Abutment, Leeds}

Failure of the waterproofing joints above the abutment was allowing chloride-laden water to run down the abutment walls and settle at their base (Fig. 2). These had penetrated the cover concrete of the walls causing significant corrosion of the steel reinforcement.

Following some localised repairs, an array of Size-2 galvanic anodes were embedded in cored holes across the whole wall in a grid configuration at a spacing of $300 \mathrm{~mm}$. Two small areas of 9 anodes $(3 \times 3)$, one at the top end of the abutment (Zone-1) and one at the base of the abutment (Zone-2) were not connected directly to the steel reinforcement but, via a cable, were taken to a junction box/monitoring unit where an external controlled 
connection was made to the steel reinforcement. Two embeddable reference electrodes were positioned, one in the centre of 4 anodes and one in-between 2 anodes in each monitored area in order to record potentials at various stages.

As in Site-1, results were collected over a period of 15 years with the anodes still in operation.

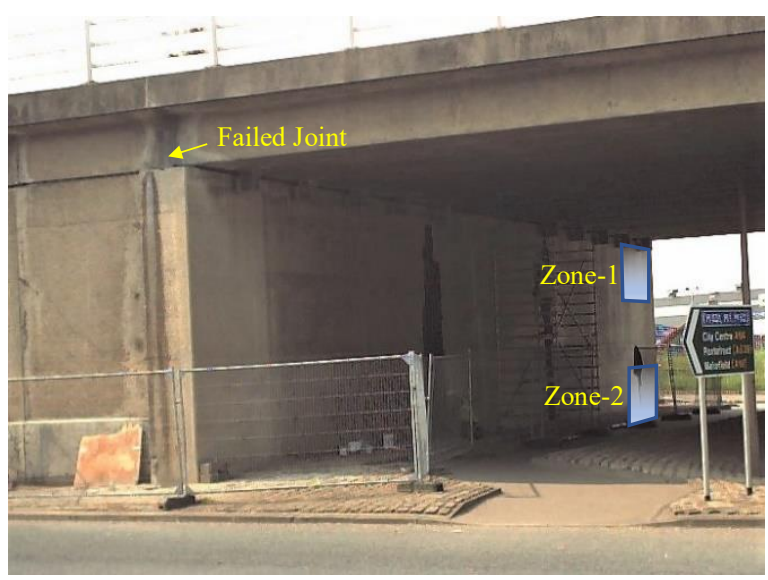

Figure 2 Abutment wall of bridge protected by an array of galvanic anodes showing Monitored Zones 1 and 2 .

\subsection{Site-3, Groby Bridge, Leicestershire}

The third site was a bridge in Leicestershire which, owing to the failure of the joints, had suffered from chlorideinduced corrosion, cracking and spalling of the cover concrete [6]. All affected concrete was removed up to about $25 \mathrm{~mm}$ behind the steel, exposing all the steel and enabling its cleaning. Galvanic anodes were then attached on the steel around the periphery of the patch at a spacing of approximately $600 \mathrm{~mm}$ before reinstating with proprietary repair mortar. Two adjacent areas were set up in a way as to allow monitoring of the current delivered to the steel by each individual anode via a junction box (Fig. 3).

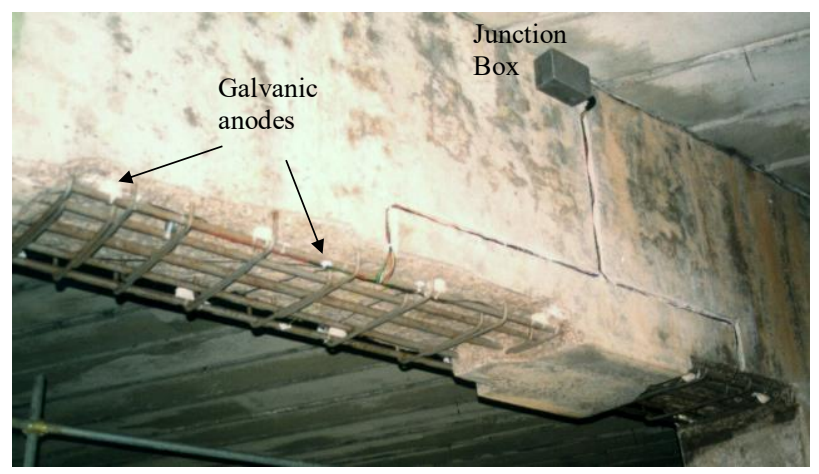

Figure 3 Galvanic anodes attached to steel reinforcement as part of a patch repair with cables from individual anodes taken to a junction box to aid monitoring of their performance.

As with the other two sites, the current was monitored with time. As no reference electrodes were embedded within the patch repairs, the steel potentials were measured from the surface in a grid configuration both while the current was on and after 24-hour depolarisation following interruption of the current. The IR-drop was estimated from instant-off readings on two marked points on the surface away from the anodes, but this was often less than $10 \mathrm{mV}$.

Results were collected over a period of 19 years. As in the case of the other two sites, monitoring is continuing.

\section{Results from the monitored sites}

The variation of current density by steel area delivered by all anodes over the equivalent area in Site-1, including $300 \mathrm{~mm}$ beyond the edge of the line of anodes, is shown in Figure 4. Overall, the current density has been decreasing with time with the larger Size-2 anodes constantly delivering a higher current to the reinforcement.

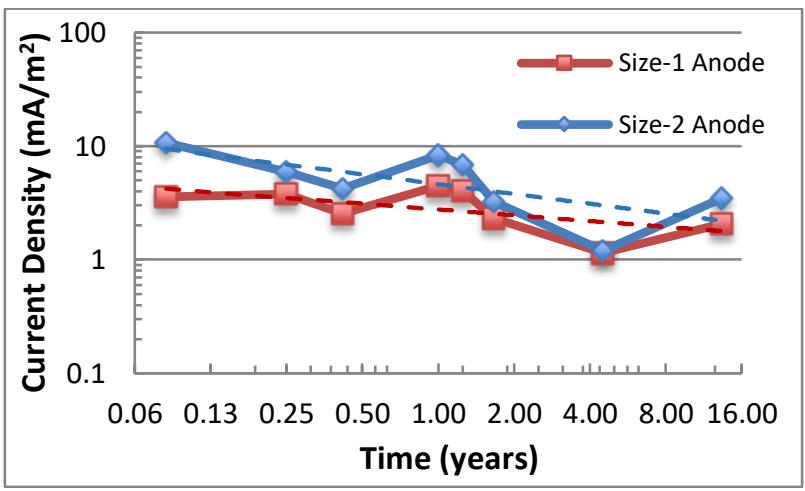

Figure 4 Current density by steel area delivered by the anodes with time to the steel reinforcement in Site-1

A similarly decreasing current density was observed in Site-2 (Fig. 5); this time, even though the anodes were the same size in both zones, a higher current density was observed throughout in the lower Zone-2. It is believed to have been influenced by the wetter and higher chloridecontaining environment of the zone at the base of the abutment as water had tended to remain there for longer periods. It is also evident that the current was reducing at a faster rate in Zone-1, suggesting a partial drying of the abutment at the higher level. The apparent sudden drop in current density at around 2 years was caused by a lower temperature (see also Fig. 6).

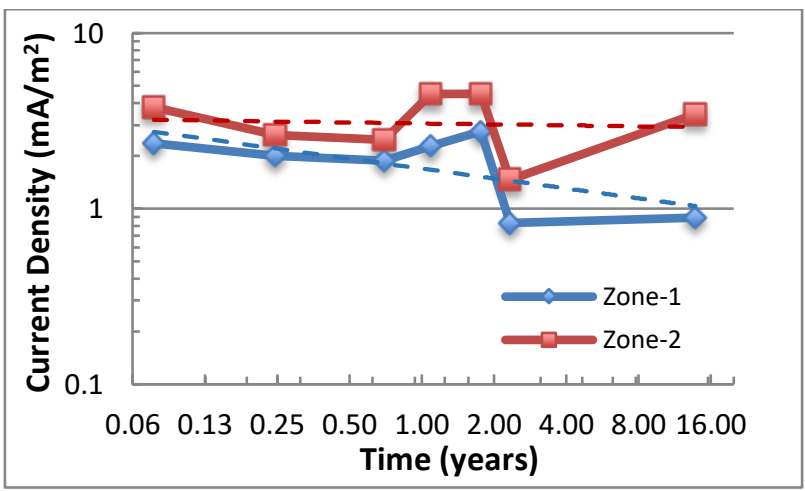

Figure 5 Current density by steel area delivered by the anodes with time to the steel reinforcement in Site-2. 
The mean current density of the 12 anodes within the two adjacent patch repairs in Site-3 was also seen to be decreasing with time (Fig. 6). As more frequent readings were taken at the early stages of the monitoring, the effect of temperature on the current density is seen very clearly, summer readings being significantly higher than winter readings.

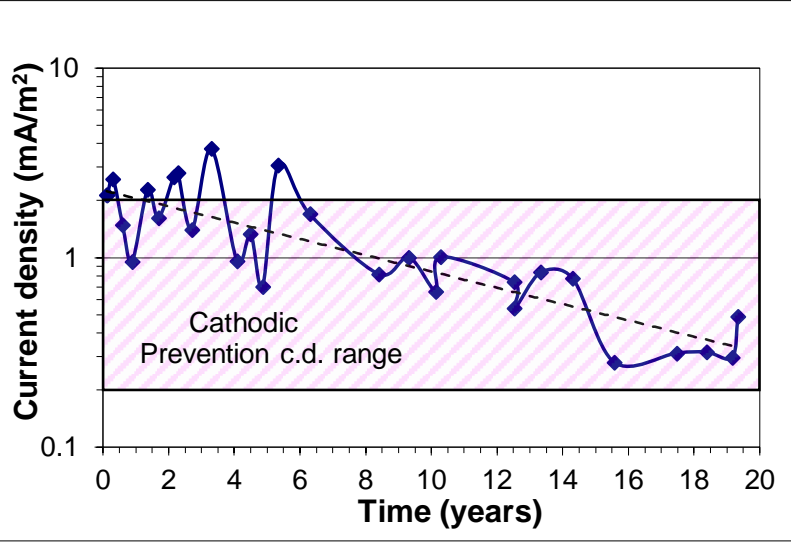

Figure 6 Mean current density by steel area delivered with time by the anodes to the steel reinforcement in Site-3

\section{Analysis of Site Results}

Analysis of the results has revealed some very interesting relationships and trends. Plotting the logarithm of current density against the depolarisation at the equivalent time indicates a strong relationship as shown in Figures 7 and 8. In Site-1 (Fig. 7), where two different size anodes were utilised on similar adjacent abutments, the slope of the plots appear to be almost identical, the only obvious difference being the higher depolarisations, mainly beyond $100 \mathrm{mV}$ up to a high of $145 \mathrm{mV}$, achieved by the larger Size-2 anodes which were able to deliver a higher current throughout. Depolarisation achieved with the smaller, Size-1, anodes was overall less and lay within a range of $70 \mathrm{mV}$ and $120 \mathrm{mV}$.

The relationship between current density and depolarisation in Site-2 was found to be significantly different for the two zones (Fig.8). Somewhat lower overall current densities attained in Zone-1 had achieved significantly higher depolarisation values $(70-115 \mathrm{mV}$ for current densities of $0.85-2.75 \mathrm{~mA} / \mathrm{m}^{2}$ ) compared to Zone-2 (60-95 $\mathrm{mV}$ for current densities of $\left.1.5-4.5 \mathrm{~mA} / \mathrm{m}^{2}\right)$.

Such logarithmic, non-linear, polarisation behaviour is described by the Butler Volmer equation (eq. 1). The formula should allow utilisation of the depolarisation and current density values to determine an apparent corrosion current density.

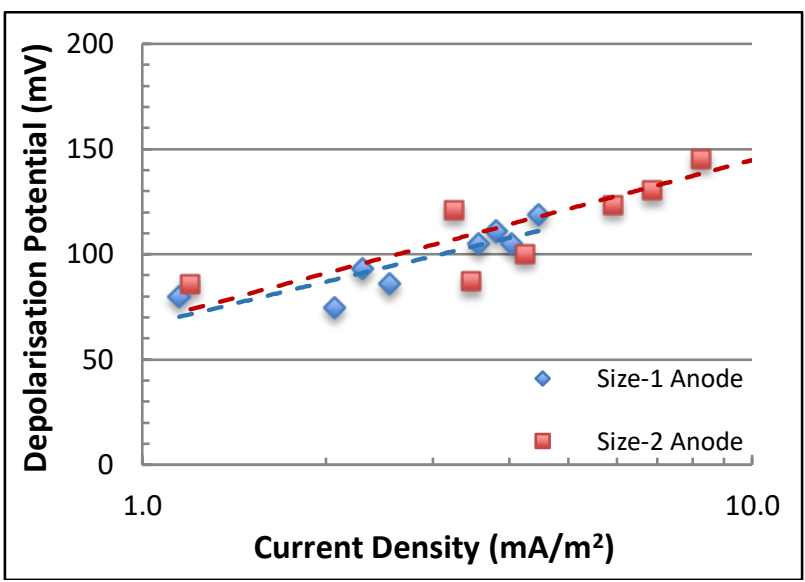

Figure 7 Relationship between current density and depolarisation potential for Site-1.

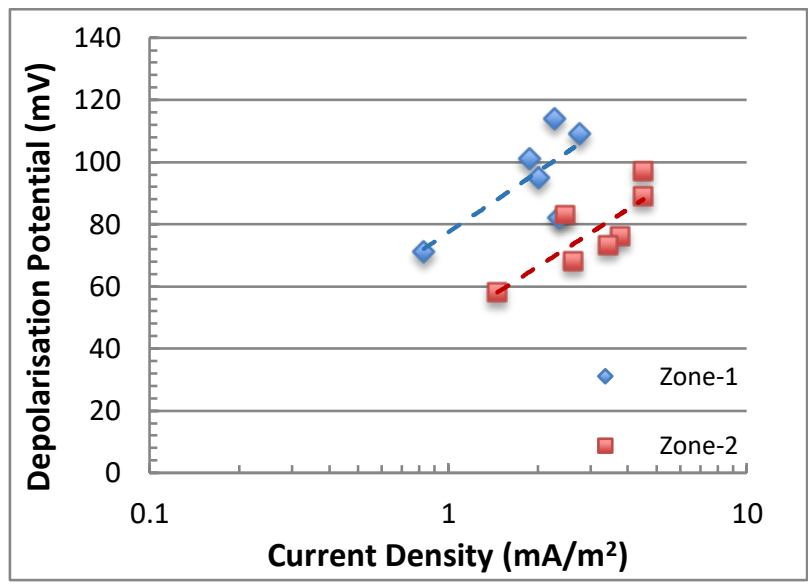

Figure 8 Relationship between current density and depolarisation potential for Site-2

$$
i_{\operatorname{corr}(a p p)}=\frac{i_{a p p l}}{\exp \left(\frac{2.3 \eta}{\beta a}\right)-\exp \left(\frac{-2.3 \eta}{\beta c}\right)}
$$

Where,

$$
\begin{aligned}
& i_{\text {corr (app) }}=\text { apparent corrosion current density, } \\
& i_{\text {appl }}=\text { applied current, i.e. current density, } \\
& \eta \quad=\text { potential shift, i.e. depolarisation potential, } \\
& \beta a=\text { Anodic Tafel Constant (assumed as } 120 \mathrm{mV}), \\
& \beta c=\text { Cathodic Tafel Constant (assumed as } 120 \mathrm{mV} \text { ). }
\end{aligned}
$$

For Site-1, the calculated apparent current density values are plotted against time in Figure 9. Within experimental error, $i_{\text {corr (app) }}$ appears to be unchanged for both abutments over the whole timescale, ranging within $0.25-0.65 \mathrm{~mA} / \mathrm{m}^{2}$. 


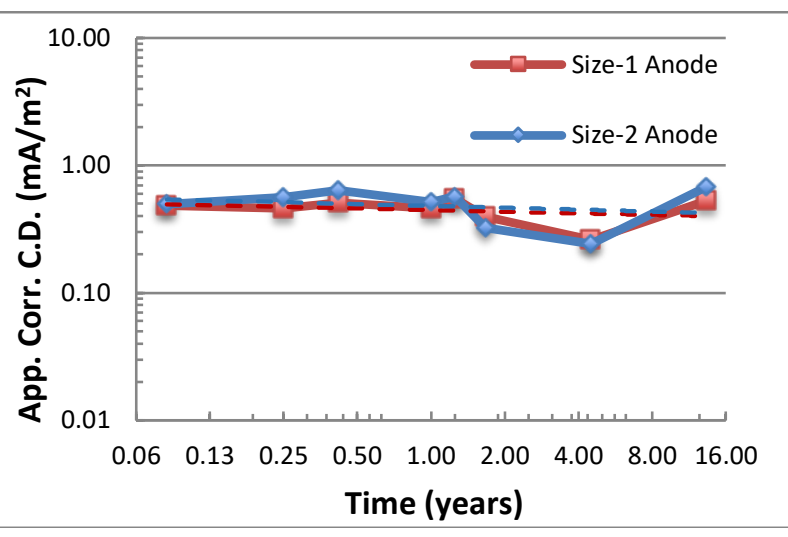

Figure 9 Variation of calculated apparent corrosion current densities with time in Site-1

In Site-2, the results reveal something different (Fig. 10). While the results of Zone-2 appear very similar to Site-1 $\left(0.55-0.95 \mathrm{~mA} / \mathrm{m}^{2}\right)$, Zone- 1 shows a decreasing trend with time, $i_{\text {corr }(a p p)}$ falling from around $0.5 \mathrm{~mA} / \mathrm{m}^{2}$ to less than $0.1 \mathrm{~mA} / \mathrm{m}^{2}$.

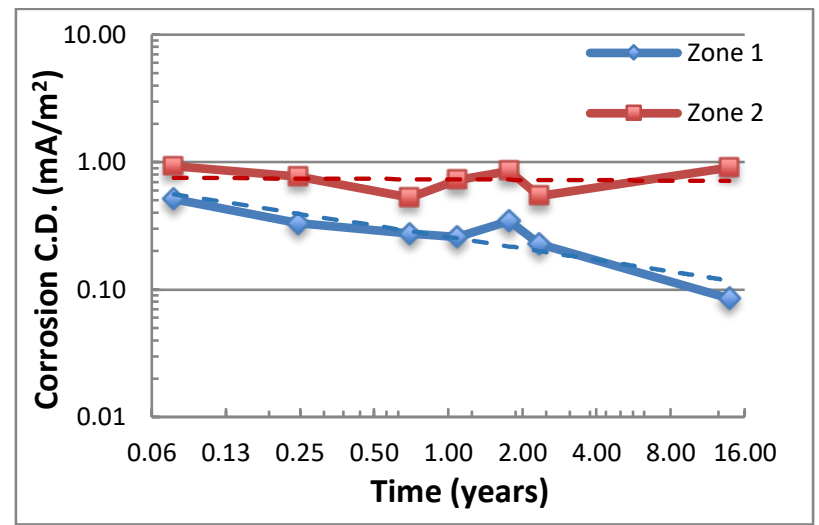

Figure 10 Variation of calculated apparent corrosion current densities with time in Site-2

As was observed in Figure 8, a low current density was inducing high depolarisation values. This is indicative of low corrosion levels of the steel which, with time, as seen in Figure 10, became more passive with the environment possibly becoming drier. In all the other conditions (Figs $9 \& 10$ ), the level of corrosion remained relatively stable.

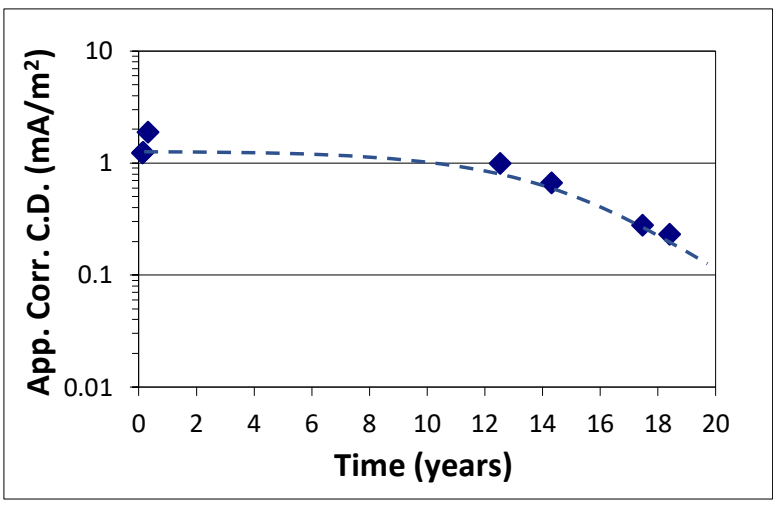

Figure 11 Variation of calculated apparent corrosion current densities with time in Site-3.

*All potentials are vs silver/silver chloride $0.5 \mathrm{M} \mathrm{KCl}$ reference electrode
In Site-3, the average apparent corrosion current density also reduced with time, finally falling to around $0.2 \mathrm{~mA} / \mathrm{m}^{2}$ (Fig. 11). This correlates well with the 24-hour depolarised corrosion potentials which became more noble with time (Fig. 12).

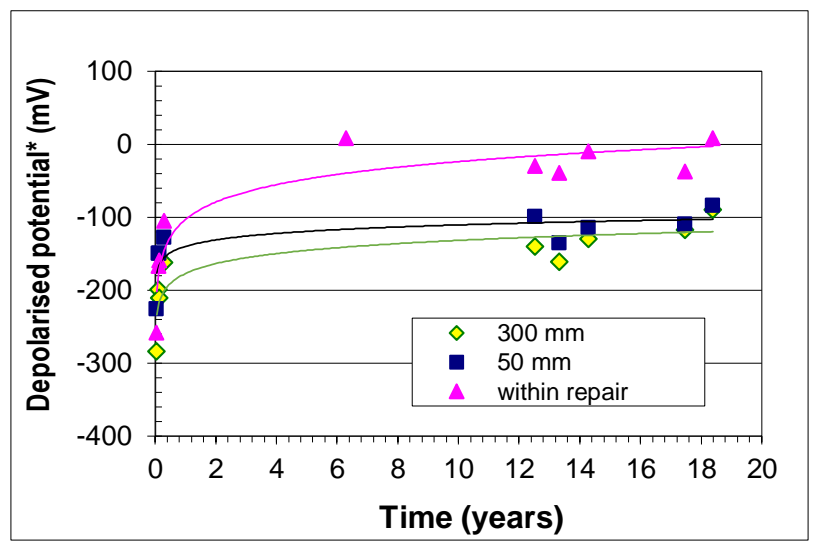

Figure 12 Depolarised potential with time within and up to 300 $\mathrm{mm}$ from the edge of the repair

Combining all the values and plotting the apparent corrosion current density against the depolarised potential $^{*}$, i.e. the steel potential 24 hours after disconnection of the anodes, a reasonable correlation is observed $(r=0.74)$ with a cathodic slope of $150 \mathrm{mV} /$ decade, close to the assumed cathodic Tafel slope of $120 \mathrm{mV} /$ decade (Fig. 13). Two points on the graph appear to fall outside the $95 \%$ confidence intervals. In fact, both these points were obtained when depolarisation potentials exceeding $150 \mathrm{mV}$ at current densities above 20 $\mathrm{mA} / \mathrm{m}^{2}$ during an externally induced applied current. The two points exhibiting lower corrosion potentials were the same two conditions prior to the induced current in a corrosive state. These were not part of the three site conditions described but part of a separate site trial involving a two-stage $\mathrm{CP}$ process [7].

If a depolarised potential of $-150 \mathrm{mV}$ is assumed to signify passivity of the steel reinforcement, the equivalent $i_{\text {corr }(a p p)}$ value appears, from Figure 13, to be around 0.6 $\mathrm{mA} / \mathrm{m}^{2}$ but owing to the variability of the results could arguably lie within a range of $0.2-2 \mathrm{~mA} / \mathrm{m}^{2} \quad(95 \%$ confidence interval).

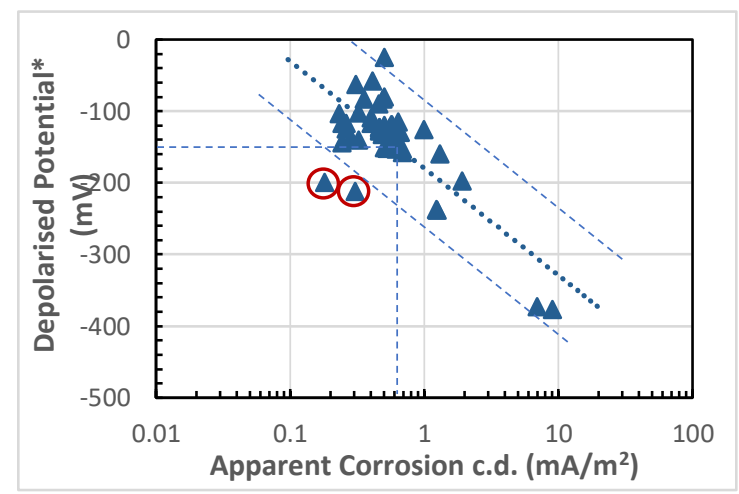

Figure 13 Relationship between apparent corrosion current density and 24-hour depolarised potential. 


\section{Results from laboratory investigations}

Experiments were run in the laboratory in an attempt to verify the relationship between applied current and resulting depolarisation, as observed in the site results. Specimens of the sort depicted in Figure 14 and reported elsewhere $[7,8]$ were employed for the studies.

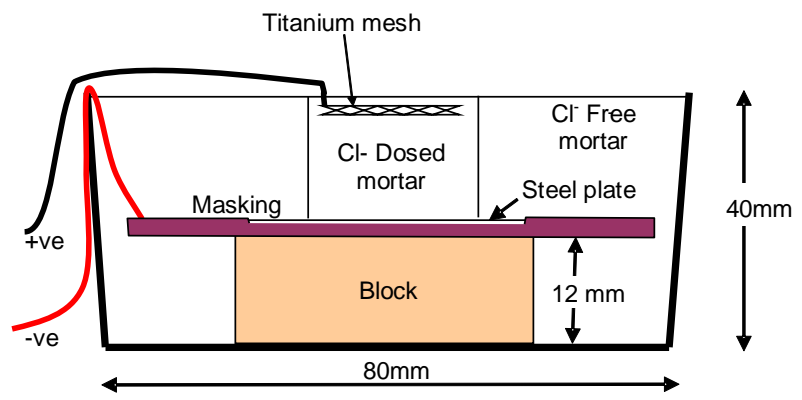

Figure 14 Schematic diagram of laboratory steel-mortar specimens

Steel plates in mortar, partially dosed with $2-4 \%$ chloride, were pre-corroded to various levels by applying anodic polarisation to various degrees, as detailed in an earlier publication [8]. They were then cathodically protected over several weeks at constant current densities ranging between $20 \mathrm{~mA} / \mathrm{m}^{2}$ and $50 \mathrm{~mA} / \mathrm{m}^{2}$ (steel surface area) until repassivation of the steel was achieved. The current was interrupted on a weekly basis. The data recorded included the current density, the 24-hour depolarisation potential and the 24-hour depolarised potential. Linear polarisation was also performed while the steel plates were in a 24-hour plus depolarised state.

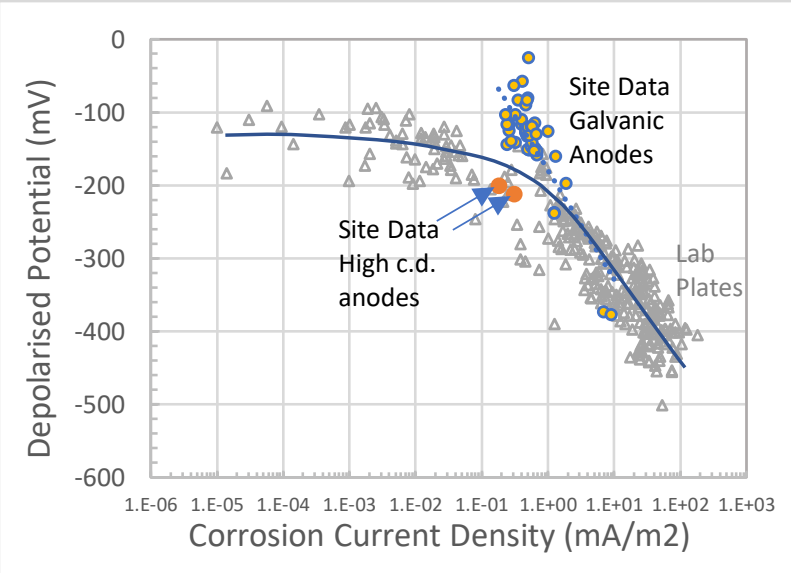

Figure 15 Apparent corrosion current density versus depolarised potential for all laboratory samples compared to site data from Fig. 13.

A whole mass of results obtained from all the tested samples, irrespective of level of pre-corrosion, applied current density and chloride dosing status, when plotted in a single graph appear to fall, within experimental error, on a single curve (Fig. 15). At the higher corrosion condition and lower current deliveries, the points appear to form an extension of the straight line obtained with the site results (Fig.13). As $i_{\text {corr(app) }}$ approaches what may be considered as passivation, as indicated by the depolarised potentials, the line curves away and eventually flattens horizontally with the depolarised potential remaining relatively constant at around $-150 \pm 50 \mathrm{mV}$ over a range of at least four orders of magnitude. It is revealing that the two points from the high current high polarisation data (Fig. 13) also appear to fall on the curve in Figure 15. A reason for this behaviour is suggested below.

It is often assumed that activation control is in operation during cathodic polarisation of steel in concrete. For this to be true, oxygen migrating to the cathodic site must be able to replace the consumed oxygen as indicated by the most likely cathodic reaction (eq. 2).

$$
1 / 2 \mathrm{O}_{2}+\mathrm{H}_{2} \mathrm{O}+2 \mathrm{e}^{-} \rightarrow 2 \mathrm{OH}^{-}
$$

This may be true at low cathodic current densities, depending on factors such as porosity and level of saturation of the concrete, but as the cathodic current increases, the reaction will gradually change to diffusion control and depend on the speed of oxygen replenishment at the cathode.

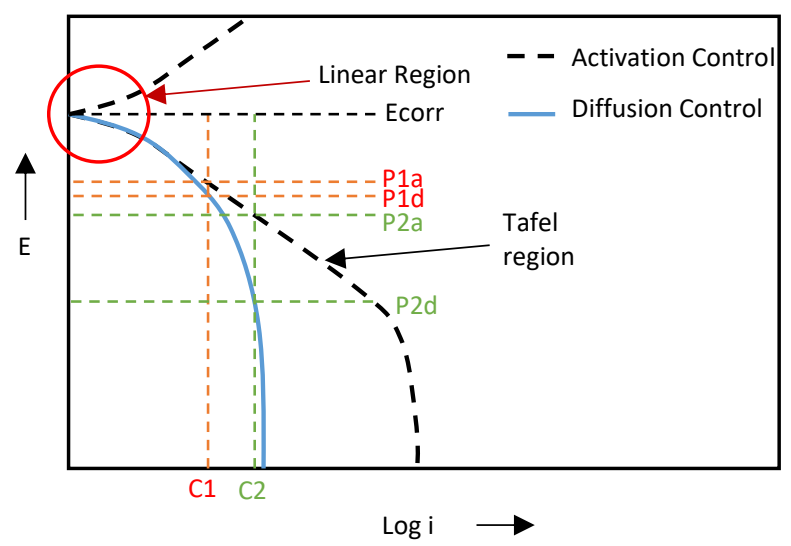

Figure 16 Schematic of cathodic polarisation showing the difference between activation control and diffusion control.

The different behaviour between activation control and diffusion control is illustrated in Figure 16. While the level of polarisation away from Ecorr is not very different when the applied current, $\mathrm{C} 1$, is low (P1a for activation control and P1d for diffusion control), the difference is greatly exaggerated at the higher current, $\mathrm{C} 2$, where the level of polarisation under activation control is much lower (Ecorr to P2a) than that achieved under diffusion control (Ecorr to P2d). This exaggerated level of polarisation under diffusion control is translated to a lower $i_{\text {corr (app) }}$ as calculated by the Butler Volmer equation (eq. 1) since the equation assumes Tafel behaviour and, therefore, activation control. Alternatively, or in addition, the cathodic behaviour of highly passive steel is altered considerably as current flowing through a very dense passive film is greatly restricted and is essentially unchanging over a wide range of polarised potentials leading to very high polarisation levels with slight increases in applied current.

In the case of the site results, with depolarisation levels between $60 \mathrm{mV}$ and $140 \mathrm{mV}$ achieved with current densities in the region of $0.8-8 \mathrm{~mA} / \mathrm{m}^{2}$ (Figs $7 \& 8$ ), polarisation may be mainly under activation control 
leading to the logarithmic relationship obtained in Figure 13. The laboratory specimens were subjected to higher current densities $\left(20-50 \mathrm{~mA} / \mathrm{m}^{2}\right)$ where diffusion control is more likely to be prevalent leading to the reduced apparent corrosion current densities seen in Figure 15. As the cathodic current in the experiments passivated the steel surface to ever greater levels, polarisation became much easier to achieve [3] leading to the apparently minute corrosion current densities observed.

That polarisation becomes easier with enhanced passivation can be seen in Figure 17. The level of measured depolarisation increased significantly as more cathodic charge was delivered to the steel at a constant current density of $50 \mathrm{~mA} / \mathrm{m}^{2}$. Both sets of specimens were pre-corroded with an anodic current density of $20 \mathrm{~mA} / \mathrm{m}^{2}$ over two weeks. The more corroded samples containing $4 \%$ chloride by weight of cement showed a slower response, but both became more passive over the total delivered charge of $120 \mathrm{kC} / \mathrm{m}^{2}$ as indicated by the depolarised potentials (Fig. 18). An increasing alkali concentration and reducing chloride level at the steel surface caused by polarisation are thought to reduce the corrosion risk $[3,8]$.

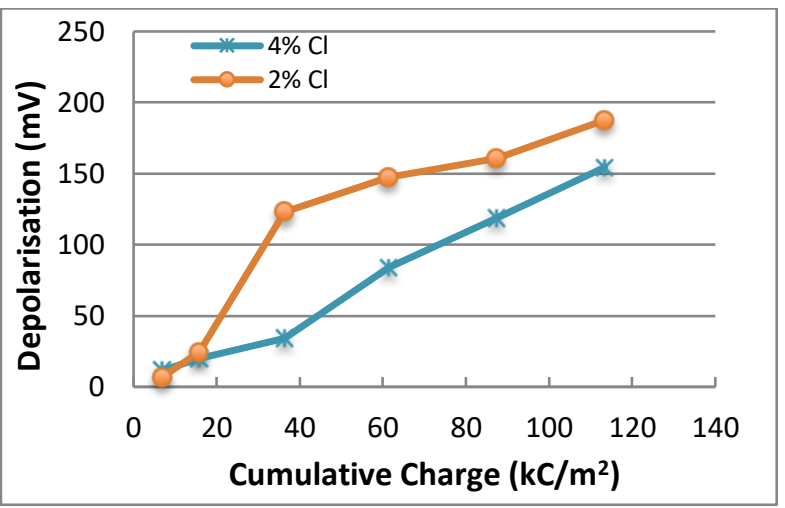

Figure 17 Increased level of depolarisation achieved with cumulative applied charge at a constant cathodic current density of $50 \mathrm{~mA} / \mathrm{m}^{2}$.

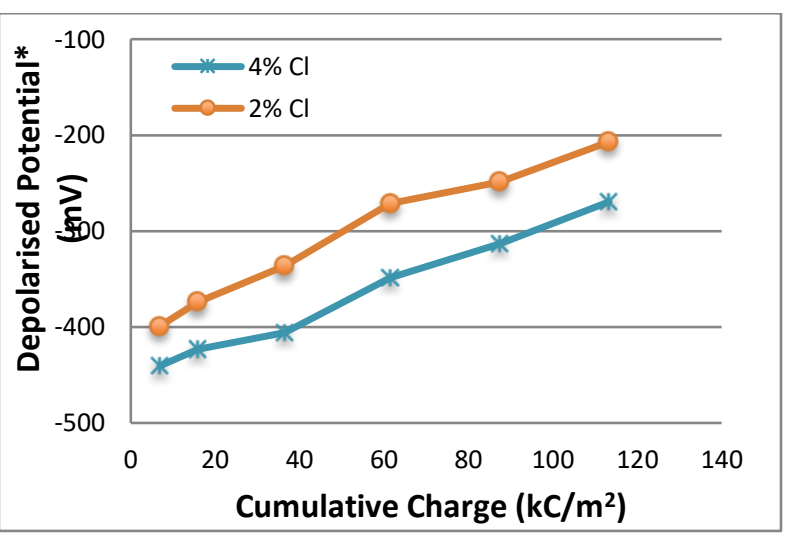

Figure 18 Gradual passivation achieved with cumulative applied charge at a constant cathodic current density of $50 \mathrm{~mA} / \mathrm{m}^{2}$.
Corrosion current densities determined by linear polarisation measurements on the steel plates just after depolarisation were compared with $i_{\text {corr(app) }}$ over the straight-line region of Figure 15.

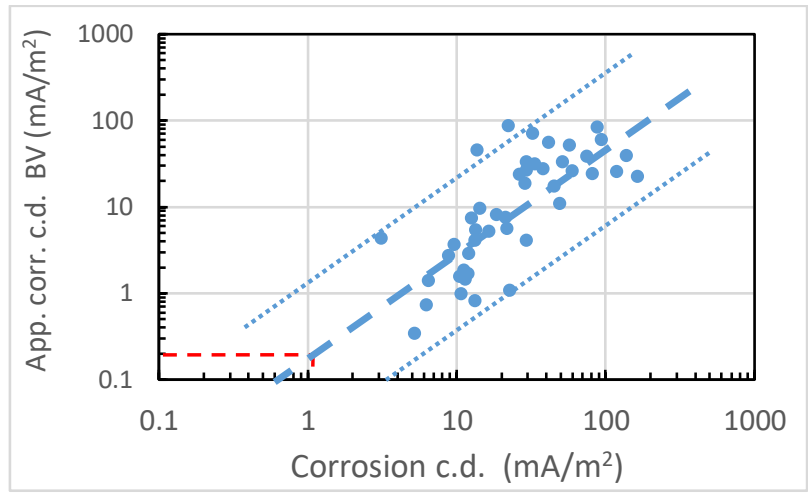

Figure 19 Correlation between corrosion current densities determined either by linear polarisation (Stern \& Geary equation) or by non-linear polarisation (Butler Volmer equation).

The results (Fig. 19) suggest that a correlation exists $(\mathrm{r}=0.75)$ between the two sets of calculated values but, at the lower corrosion current densities the two sets diverge. At icorr $=1 \mathrm{~mA} / \mathrm{m}^{2}$, as determined by linear polarisation, considered to be the limit where passivity of the steel is demonstrated [9], the equivalent $i_{\text {corr(app) }}$ value is nearer $0.2 \mathrm{~mA} / \mathrm{m}^{2}$. Although this value is lower than $0.6 \mathrm{~mA} / \mathrm{m}^{2}$ that appears to be the critical apparent corrosion current density in Figure 12, the two set of results certainly overlap if the $95 \%$ confidence intervals are considered.

Any values calculated in this way are only likely to be accurate within an order of magnitude, especially if error factors such as total affected area of steel during polarisation and variation in localised resistivity are considered. It is encouraging, however, that for a single monitored area (Figs 9-11), where the assumed steel area receiving current is essentially constant and the potential is always measured from a fixed position, even if the calculated $i_{\text {corr(app) }}$ value is assumed to be erroneous, the trend appears to be realistic. Such a trend could be used as an indicator of the performance of the cathodic protection system.

As the depolarised potential also follows a trend which can indicate lowering corrosion activity (Figs. 12 $\& 18)$, it is suggested that a combination of $i_{\text {corr(app }) \text { and the }}$ depolarised potential viewed together as trends with time can be very helpful in assessing the performance of the protective system. Both these parameters can be easily determined from measurements that are already taken during monitoring of the system, viz., 24-hour depolarisation and depolarised potential in combination with the applied current density. 


\section{Conclusions}

It is suggested from analysis of site and laboratory results in this study that a combination of an apparent corrosion

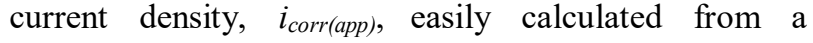
combination of applied current density and 24-hour depolarisation for the equivalent current density can be a useful indicator of the performance of the cathodic protection system.

A constant or reducing $i_{\text {corr (app) }}$ trend with time in combination with an upward trend (less negative) of 24-hour depolarised potential can be viewed as an indicator that the system is in a good operating condition achieving adequate protection of the steel reinforcement.

These parameters can be used in order to decide if protection is deemed to be adequate when the depolarisation criteria of ISO EN 12696 are not met.

The results further indicated that adequate polarisation leads to a gradual decrease in the corrosion rate of the reinforcement and can, if sufficient charge is delivered to the steel at an appropriate current density, lead to passivation of the steel.

\section{References}

1. ISO BS 12696:2016 "Cathodic protection of steel in concrete.

2. NACE SP0290:2007 "Impressed Current Cathodic Protection of Reinforcing Steel in Atmospherically Exposed Concrete Structures".

3. P Pedeferri "Cathodic Protection and Cathodic Prevention" Construction \& Building Materials, 10, 5, (1996) pp. 391-402.

4. NACE International Publication 35108 "One Hundred Millivolt $(\mathrm{mV})$ Cathodic Polarisation Criterion", 2008

5. J.E. Bennett, T.A. Mitchell, "Depolarization Testing of Cathodically Protected Reinforced Steel in Concrete" MP 30, 12 (1990): pp. 20-25.

6. G Sergi "Ten-year results of galvanic sacrificial anodes in steel reinforced concrete" Materials and Corrosion, 62, 2 (2011) pp 98-104.

7. G Sergi \& A M G Seneviratne "Extending residual service life of steel reinforced structures by the use of galvanic anodes" Concrete Solutions, M Grantham, P A M Basheer, B Magee \& M Soutsos Eds, CRC Press, Taylor \& Francis Group, 2014, pp. 229-235.

8. N Rathod, G Sergi, G Seneviratne \& P R Slater "A suggestion for a two-stage corrosion mitigation system for steel reinforced concrete structures" EUROCORR 2008, ICE Krakow, 9-13 September 2018.

9. C. Andrade, C. Alonso, J Gulikers, R. Polder, R. Cigna, O. Vennesland, M. Salta \& A. Beharinaivo "Test methods for on-site corrosion rate measurement of steel reinforcement in concrete by means of the polarisation resistance method"
Materials and Structures (2004) 37, 273, pp. 623643. 